\title{
e-interview
}

\section{Robert H. Belmaker}

Robert H. Belmaker is Professor of Psychiatry at Ben Gurion University of the Negev, Beersheva, Israel. He studied at Harvard and Duke Universities, and the National Institute of Mental Health (NIMH). His special interests include bipolar disorder, schizophrenia and sexual disorders.

If you were not a psychiatrist, what would you do?

I could see myself teaching philosophy or easily enjoying a career in biblical archeology.

Do you feel stigmatised by your profession?

have never felt stigmatised as a psychiatrist and have always felt myself to be an object of considerable interest at parties and social events.

What are your interests outside of work?

My family of six children and growing brood of grandchildren are my true passion but tours of archeology and scuba-diving worldwide are also great fun.

Who was your most influential trainer, and why?

Jack Rhoads at Duke University was my psychotherapy supervisor and provided me with a great number of critical pieces of advice: 1) A practical piece of advice is worth more than many theories; 2) No theory explains everything; use each one when it's useful; 3) You can't cure everyone; 4) Don't over-promise; and 5) If it doesn't work, try something else.

What job gave you the most useful training experience?

As a clinical associate at NIMH 1972-1974

I was exposed to the greatest minds and infinite freedom of enquiry.

Which publication has influenced you most?

Seymour Kety's 1967 paper in the New England Journal of Medicine where he discussed biological theories of mental illness. While a convinced believer that biological causes would be found and a key researcher of biological causes himself, Kety criticised unmercifully all the biological theories of the time and pronounced each of them unproven. This sort of skepticism is gone, as people nowadays seem to believe their own grant proposals as facts even before they have carried out the experiments.

How has the political environment influenced your work?

I wake up every morning grateful to live in a free society where the wide range of beliefs that I have professed has never led to any negative repercussions.

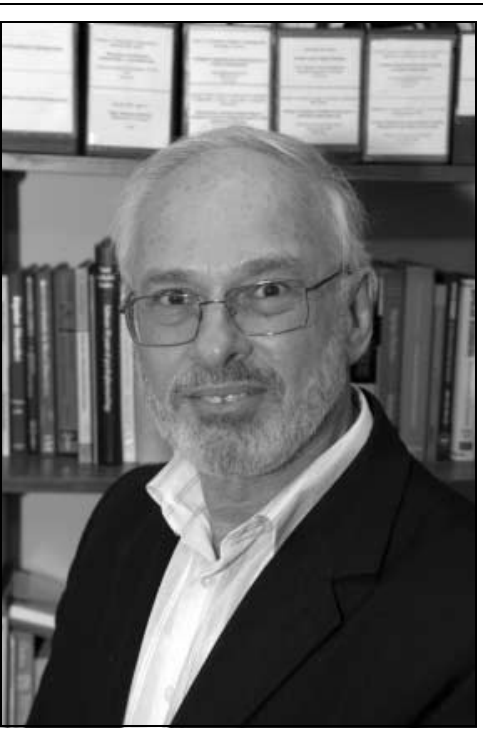

in any current diagnostic system or biological theory.

What are the main ethical problems that psychiatrists will face in the future?

I think the key ethical issue will be whether we will use our medical and scientific training to continually update and evaluate our treatments or whether we will allow ourselves to believe in those treatments that are easier, more profitable or more popular to administer.

Do you think psychiatry is brainless or mindless?

I think psychiatry is the most fascinating and exhilarating area of study and practice there could possibly be

What is the role of the psychiatrist in rebuilding healthcare systems? My experience is that psychiatry will never have the central power in medical care systems but must learn to adjust itself to the medical and surgical specialties that are seen by the public as the central paradigm of medical care. \section{opportunity facing the profession?}

What is the most promising We are responsible for the greatest achievement of the human species, and perhaps all of creation: the human mind. We must avoid oversimplifying it, in either biological or psychological directions, and try to reduce suffering while respecting deeply the object of our ministrations

What is the greatest threat?

Self-interest is clearly the greatest threat here. I can never get over hearing at medical meetings the argument that a particular diagnostic concept, pharmaceutical treatment or other therapy is best 'because it makes us true doctors and is good for the psychiatric profession'.

What single change would substantially improve quality of care? Education, education, education.

\section{What conflict of interest} do you encounter most often? Clearly one is invited to speak most often when one's ideas are congruent with those who do most of the inviting

What is the role of the psychiatrist in countries emerging from conflict? I would like to believe that I live in a country emerging from conflict but so far it seems that we are still deeply embedded in conflict. My efforts during the Oslo process to collaborate with Palestinian psychiatrists on a schizophrenia research project funded by Germany did not, in my opinion, have a significant effect.

What is the most important advice you could offer to a new trainee? Read widely in all areas including literature, philosophy and biology, and do not believe
What single change to mental health legislation would you like to see? I think the process of involuntary psychiatric hospitalisation should be taken out of an adversarial model and provision made for preventive involuntary hospitalisation at the request of families, with psychiatric recommendation and with safeguards built into a medical framework, and not a judiciary or legal one.

\section{What single area of psychiatric} research should be given priority? I think the era of optimism that we will soon find genes for psychiatric disorders is coming to an end. I also think that imaging studies are likely to find correlates of particular emotional states but I don't see how they will lead us to causes or treatments. I think we need to develop a healthy respect for the complexity of the human brain and mind, and will need to do the slogging, difficult work gene by gene, brain area by brain area and enzyme by enzyme for many years to come. It is dangerous in my opinion to promise the public quick fixes in the next few years by either genetics or imaging.

\section{How would you like}

to be remembered?

I used to say that I wanted my tombstone to say 'All his references were correct' but nowadays with Endnote this would be no great compliment.

Dominic Fannon

doi: 10.1192/pb.bp.108.019851 